\title{
Marshall's Reagent: Origins, Modifications, and New Applications
}

\author{
A. O. Benscoter* and M.J. Perricone* \\ * Department of Materials Science and Engineering, Lehigh University, 5 East Packer Avenue, \\ Bethlehem, PA 18015
}

W.A. Marshall[1] originally developed a hydrogen peroxide based solution to non-electrolytically polish steel in complex shapes to prepare them for decorative coatings of nickel or chrome. This solution has subsequently been shown by many authors[2,3] to simultaneously smooth and etch the metallic sample, resulting in a bright finish in which a wide variety of microstructural detail can be observed. Composed of $8 \mathrm{~g}$ oxalic acid and $5 \mathrm{ml}$ concentrated sulphuric acid in $100 \mathrm{ml}$ water mixed with an equal volume of 100 volumes 30\% hydrogen peroxide, this chemical polishing technique reduces the extent of plastic deformation during sample preparation and fills an important niche in the metallographer's arsenal of techniques and etchants. Unlike other chemical polishing processes that result in a dull surface finish, gas is periodically evolved every few seconds from the cyclic creation and dissolution of a protective oxide film at the steel surface during the polishing/etching process.

Marshall's etchant has since been developed for a wide variety of applications, chief among them the selective etching of steel surfaces to reveal details of the microstructure for which other techniques are inadequate. A prime example is shown in Figure 1, involving Ti-stabilized steel with a bimodal grain size distribution. When this material is prepared using $2 \%$ nital, a non-descript microstructure is revealed providing little information about material properties. In contrast, Marshall's etchant readily interacts with the grain boundaries of this alloy and reveals two distinct grain size regimes within the same microstructure. Marshall's etchant can also be used to evaluate pearlitic steels (AISI 1080 steel, Figure 2), particularly pearlite colony size. Furthermore, Marshall's etchant is an excellent substitute for Picric acid, particularly in government facilities that prohibit the storage of this reagent due to safety concerns. The prior austenite grain structure of ASTM 508 quench and tempered steel can be revealed via repetitive etching and polishing with either modified Winstread's reagent ( $2 \mathrm{~g}$ picric acid, $10 \mathrm{ml}$ ethyl alcohol, $200 \mathrm{ml}$ $\mathrm{H}_{2} \mathrm{O}, 5 \mathrm{ml} 40 \%$ sodium tridecylbenzene sulfanate, 5 drops $\left.\mathrm{HCl}\right)$ [4] or modified Marshall's reagent $(1 \mathrm{ml}$ $\mathrm{HF} / 100 \mathrm{ml}$ solution), the results of which are juxtaposed in Figure 3.

Metallography has long been regarded as a combination of both art and science, though the former description unfortunately leads many scientific authors to gloss over the details of sample preparation required to reveal microstructure. As such, information about metallographic etching techniques is rather sparse in modern technical literature. In an effort to bridge this gap, this paper represents the culmination of collective metallographic experience garnered over a long career in the steel industry, and will illustrate the many and varied uses of Marshall's reagent as an aid to the next generation of metallographers.

[1] Marshall WA. A Non-Electrolytic Smoothing Treatment for Steel. J Electrodepositors' Tech Soc 1952; 28:27-46.

[2] Sachs K, Bunton JD. Non-Destructive Metallography of Plain Carbon Steels. Metallurgia 1955; 52(10):205-209.

[3] Hawkins DN. An Etchant for Revealing the Substructure in Low-Carbon Steels. Metallography $1981 ; 14: 61-68$. 
[4] Bramfitt, BL, Benscoter, AO. Metallographer's Guide: Practices and Procedures for Irons and Steels. ASM International, 2004. 354p.

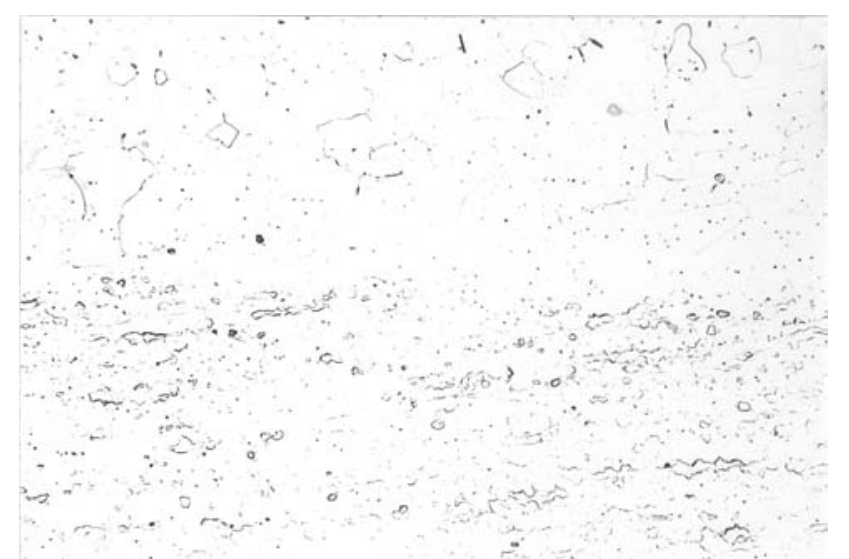

$20 \mu \mathrm{m}$

2

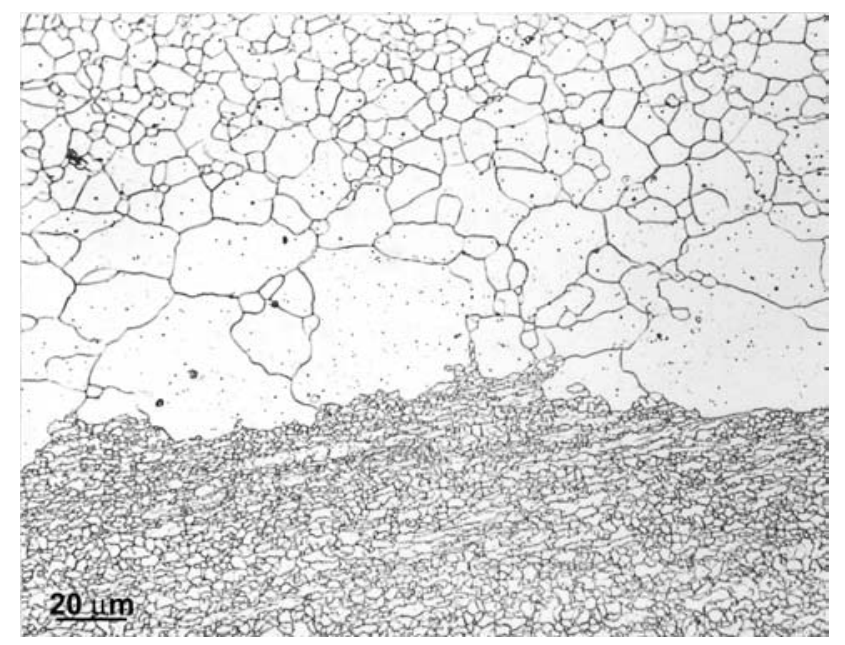

Figure 1. Titanium-stabilized steel etched with (left) $\%$ Nital and (right) Marshall's etchant.
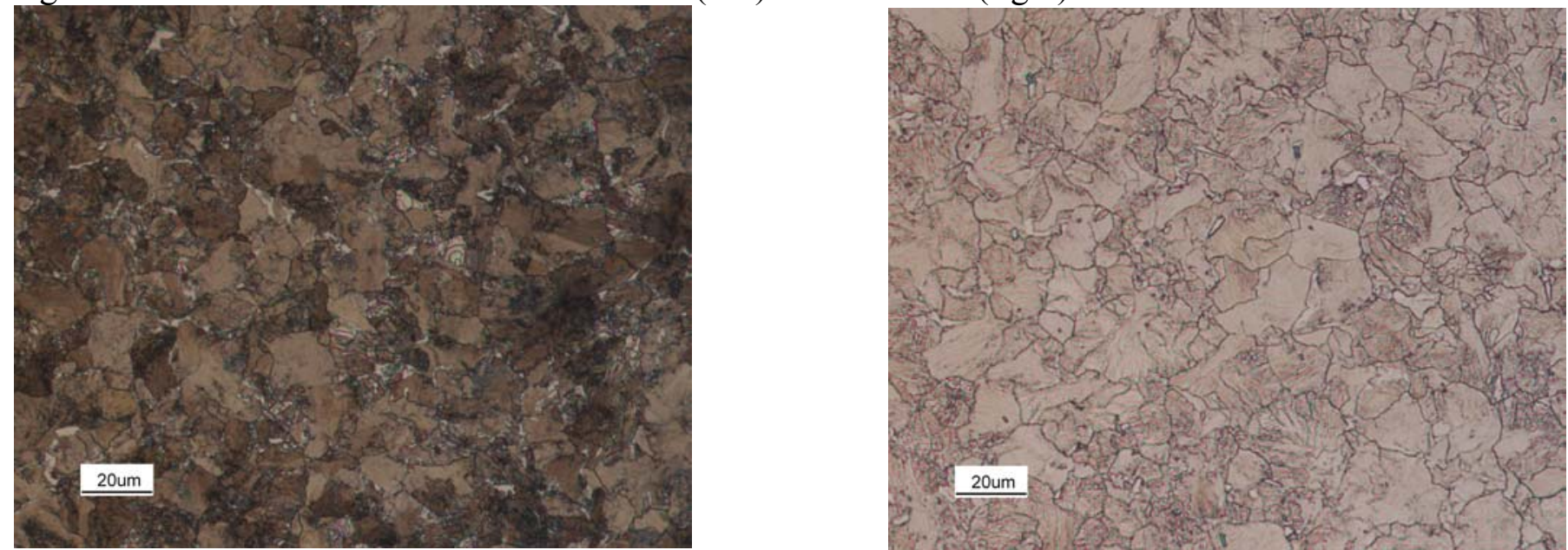

Figure 2. Pearlite colony size of AISI 1080 steel with (left) 4\% Picral and (right) Marshall's reagent.
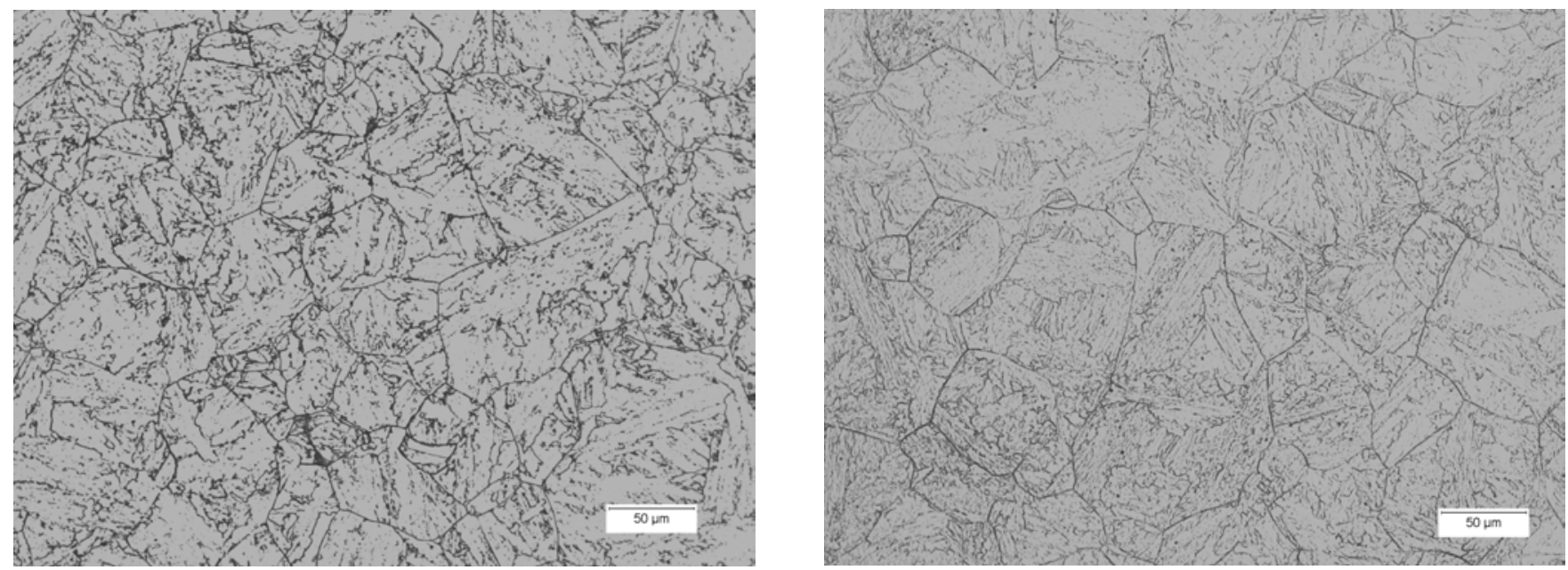

Figure 3. Prior austenite grain structure of ASTM 508 quench and tempered steel etched with (left) modified Winstread's reagent containing picric acid and (right) modified Marshall's with HF. 